\title{
Antinociceptive effects of Cremophor EL orally administered to mice
}

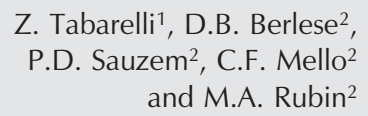

\author{
1Departamento de Fisiologia, Centro de Ciências da Saúde, and \\ 2Departamento de Química, Centro de Ciências Naturais e Exatas, \\ Universidade Federal de Santa Maria, Santa Maria, RS, Brasil
}

\begin{abstract}
Correspondence

M.A. Rubin

Departamento de Química

Centro de Ciências Naturais e Exatas

Universidade Federal de Santa Maria

97105-900 Santa Maria, RS

Brasil

Fax: +55-55-220-8031

E-mail: marubin@smail.ufsm.br

Research supported by CNPq

(Nos. 520189/97-3 and 351127/97-6),

PIBIC/CNPq-UFSM and FAPERGS.

Received June 25, 2002

Accepted October 14, 2002

......................

Surfactants are frequently used to improve solubilization of lipophilic drugs. Cremophor EL (CrEL) is a polyoxyethylated castor oil surfactant used to solubilize water-insoluble drugs such as anesthetic, antineoplastic, immunosuppressive and analgesic drugs, vitamins and new synthetic compounds, including potential analgesics. The antinociceptive effect of CrEL (3.2, 6.4 and $10.6 \mathrm{~g} / \mathrm{kg}$, in $10 \mathrm{ml} / \mathrm{kg}$ body weight, by gavage) on the abdominal writhing response induced by intraperitoneal administration of acetic acid $(0.8 \%, 10 \mathrm{ml} / \mathrm{kg}$ body weight) and on the tail immersion test was investigated in mice. Control animals received castor oil $(10 \mathrm{ml} / \mathrm{kg}$ body weight $)$ or saline $(0.9 \% \mathrm{NaCl}, 10 \mathrm{ml} / \mathrm{kg}$ body weight $)$. CrEL reduced nociception in a dose-dependent manner in both tests. At $10.6 \mathrm{~g} / \mathrm{kg}, \mathrm{CrEL}$ caused antinociception similar to that induced by dipyrone $(300 \mathrm{mg} / \mathrm{kg}$, by gavage) in the abdominal writhing test, and antinociception similar to that induced by morphine $(20 \mathrm{mg} / \mathrm{kg}$, by gavage) in the tail immersion test. The effect of castor oil was similar to that of saline in both assays. These data indicate that the appropriate controls should be used when evaluating the effects of potential antinociceptive agents dissolved in CrEL.
\end{abstract}

Cremophor EL (CrEL) is a polyoxyethylated castor oil obtained by the reaction of castor oil with ethylene oxide at a molar ratio of 1:35, which has detergent properties. Castor oil is obtained from the seeds of Ricinus communis (Euphorbiaceae) and consists primarily of the triglycerides of ricinoleic, isoricinoleic, stearic, and dihydroxystearic acids (1).

Due to its detergent properties, CrEL has been widely used to solubilize waterinsoluble drugs such as anesthetics (1), antineoplastic agents $(1,2)$, immunosuppressive agents (3), analgesics $(4,5)$, vitamins (6), and new synthetic water-insoluble compounds. Although in general CrEL is considered rela-
Key words

- Antinociception

- Cremophor EL

- Tail immersion test

- Writhing test

- Dipyrone

- Morphine tively nontoxic $(1,7)$, several reports have suggested that drugs administered in CrEL induce serious complications like anaphylactoid hypersensitivity (6) and axonal swelling, degeneration and demyelination $(2,3)$. Moreover, it has been proposed that CrEL plays a role in the etiology of the peripheral neuropathy observed after intravenous paclitaxel (2) or cyclosporin A treatment (3), and recent evidence supports the notion that $\mathrm{CrEL}$ affects nerve conduction $(2,8)$.

Although CrEL has been used as a vehicle for the intravenous administration of new antinociceptive drugs, and has been reported not to alter nociception (4), there is no 
information in the literature about the effects of orally administered CrEL on nociceptive tests. This is particularly important, since CrEL has been used as a vehicle in oral preparations (9).

In the present study we investigated whether orally administered CrEL alters the antinociceptive response of mice in the acetic acid-induced writhing and tail immersion tests.

Male albino mice (30-40 g) fasted for 12 $\mathrm{h}$ with free access to water and maintained on a 12-h light/12-h dark cycle at controlled temperature $\left(22 \pm 1^{\circ} \mathrm{C}\right)$ were used. Each animal was used only once.

CrEL was diluted in castor oil, while morphine and dipyrone were dissolved in $0.9 \%$ saline. All drugs were purchased from Sigma (St. Louis, MO, USA).

All experiments were performed in accordance with current guidelines for the care of laboratory animals and ethical guidelines for investigations of experimental pain in conscious animals (10).

The effect of CrEL on coordinated motor movements was assessed by the Rotorod test (11). Each mouse was trained to run in a Rotorod ( $3.7 \mathrm{~cm}$ in diameter, $8 \mathrm{rpm}$ ) until it could remain in the apparatus for $60 \mathrm{~s}$ without falling. Twenty-four hours after training, the animals were given castor oil $(10 \mathrm{ml} / \mathrm{kg}$ body weight, by gavage) or $0.9 \%$ saline (control group), CrEL (3.2, 6.4 or $10.6 \mathrm{~g} / \mathrm{kg}$ ), morphine sulfate ( $20 \mathrm{mg} / \mathrm{kg}$, by gavage) or dipyrone $(300 \mathrm{mg} / \mathrm{kg}$, by gavage) and $30 \mathrm{~min}$ thereafter were placed again in the Rotorod. The latency (in seconds) to fall from the apparatus was recorded up to a limit of $240 \mathrm{~s}$.

The effect of CrEL on antinociception was assessed by the abdominal writhing response induced by the intraperitoneal administration of acetic acid and by the tail immersion test. Five minutes after Rotorod evaluation, the mice were subjected to the writhing test, which was carried out by the method of Hayashi and Takemori (12). Briefly, the animals were injected with acetic acid $(0.8 \%$ in distilled water, $10 \mathrm{ml} / \mathrm{kg}$ body weight, $i p$ ), and 5 min thereafter were transferred to an open field $(28 \times 18 \times 12$ $\mathrm{cm}$ ), whose floor was divided into 15 equal areas. The number of writhes (a contraction of abdominal muscles accompanied by an elongation of the body and extension of the hind limbs), rearing responses and areas crossed with the four paws were counted over a period of $10 \mathrm{~min}$.

The tail immersion test was carried out as described by Janssen et al. (5). The animals were weighed and marked and had the last $3.5 \mathrm{~cm}$ of their tail immersed in hot water $\left(55^{\circ} \mathrm{C}\right)$, a procedure that caused them to rapidly withdraw their tail. Twenty-four hours after this habituation session, the animals were given castor oil ( $10 \mathrm{ml} / \mathrm{kg}$ body weight, by gavage) or $0.9 \%$ saline (control groups), CrEL (3.2, 6.4 or $10.6 \mathrm{~g} / \mathrm{kg}$ ), morphine (20 $\mathrm{mg} / \mathrm{kg}$ ) or dipyrone $(300 \mathrm{mg} / \mathrm{kg}$ ) and $45 \mathrm{~min}$ thereafter had their $3.5 \mathrm{~cm}$ end tail immersed again in hot water $\left(55^{\circ} \mathrm{C}\right)$. The latency to withdraw the tail was recorded in 0.1-s units with a stopwatch, and a cut-off maximum latency of $7 \mathrm{~s}$ was established in order to prevent tissue damage.

All behavioral data were scored by two observers who were not aware of the animal's treatment. There was $>90 \%$ agreement between them.

Statistical analysis of the number of writhes and ambulation scores was carried out by one-way ANOVA followed by the Student-Newman-Keuls test. Tail immersion and Rotorod latencies were analyzed by the Kruskal-Wallis H-test analysis of variance followed by the individual Mann-Whitney U-test. F values are presented only when $\mathrm{P}<0.05$. The dose-effect relationship was assessed by partitioning the sum of squares into linear, quadratic or cubic trends or by nonparametric correlation analysis.

The effect of CrEL, morphine and dipyrone administration on the number of writhes induced by acetic acid is shown in Figure 1 . Statistical analysis of the effect of CrEL $(3.2-10.6 \mathrm{~g} / \mathrm{kg})$ revealed a significant effect 
of treatment $(\mathrm{F}(3,16)=7.07, \mathrm{P}<0.004)$, and partitioning of sum of squares into trend components revealed significant linear $(\mathrm{F}(1,16)=10.38, \mathrm{P}<0.005)$ and quadratic $(\mathrm{F}(1,16)=10.59, \mathrm{P}<0.005)$ trends, indicating that the number of writhes decreased linearly or quadratically with the dose of CrEL (Figure 1A). Figure 1B shows that CrEL $(10.6 \mathrm{~g} / \mathrm{kg})$, morphine and dipyrone similarly reduced the number of writhes induced by acetic acid $(F(4,20)=9.29$, $\mathrm{P}<0.005)$. On the other hand, CrEL, morphine and dipyrone had no effect on spontaneous motor activity or on the number of rearing responses during writhing evaluation. Accordingly, the performance of the animals in the Rotorod was not affected by CrEL, morphine or dipyrone treatment (data not shown).

The effect of CrEL, morphine and dipyrone on the tail immersion latencies is shown in Figure 2. Statistical analysis of the effect of CrEL (3.2-10.6 g/ $/ \mathrm{kg}$ ) revealed a significant effect of treatment $(\mathrm{H}=8.16$, d.f. $=3$, $\mathrm{P}<0.05)$. Post hoc analysis showed that 6.4 $\mathrm{g} / \mathrm{kg}(\mathrm{U}(7,7)=8.0, \mathrm{P}<0.05)$ and $10.6 \mathrm{~g} / \mathrm{kg}$ $(\mathrm{U}(7,7)=4.0, \mathrm{P}<0.01) \mathrm{CrEL}$ increased withdrawal latencies compared to control. Spearman rank correlation coefficient analysis revealed a significant correlation between $\mathrm{CrEL}$ doses and tail immersion latencies $\left(r_{s}=0.541\right.$, $\mathrm{P}<0.01$ ), indicating a dose-effect relationship (Figure 2A). Statistical analysis of the effect of CrEL $(10.6 \mathrm{~g} / \mathrm{kg})$, morphine and dipyrone revealed a significant effect of treatment $(\mathrm{H}=15.93$, d.f. $=4, \mathrm{P}<0.005$, KruskalWallis H-test). Post hoc analysis showed that $\mathrm{CrEL}(\mathrm{U}(7,7)=8.0, \mathrm{P}<0.01)$, morphine $(\mathrm{U}(6,6)=4.0, \mathrm{P}<0.05)$ and dipyrone $(\mathrm{U}(6,6)=$ $4.0, \mathrm{P}<0.05)$ increased withdrawal latencies compared to those observed in the respective control group (Figure 2B).

CrEL has been used as a vehicle for a myriad of water-insoluble drugs, including potential antinociceptive drugs. Although some investigators have reported that intravenously administered CrEL lacks an intrin- sic antinociceptive action (4), to date no study has specifically addressed whether orally administered Cremophor causes antinociception or not. Moreover, in order to correctly interpret experimental data from antinociceptive studies, it is important to determine not only whether the vehicle has antinociceptive properties per se, but also whether it causes other effects which may confound antinociceptive evaluation, such as ataxia and sedation.

In the present study we show that orally administered CrEL causes dose-dependent antinociception, as assessed by a tonic and a phasic antinociceptive test. The fact that $\mathrm{CrEL}$

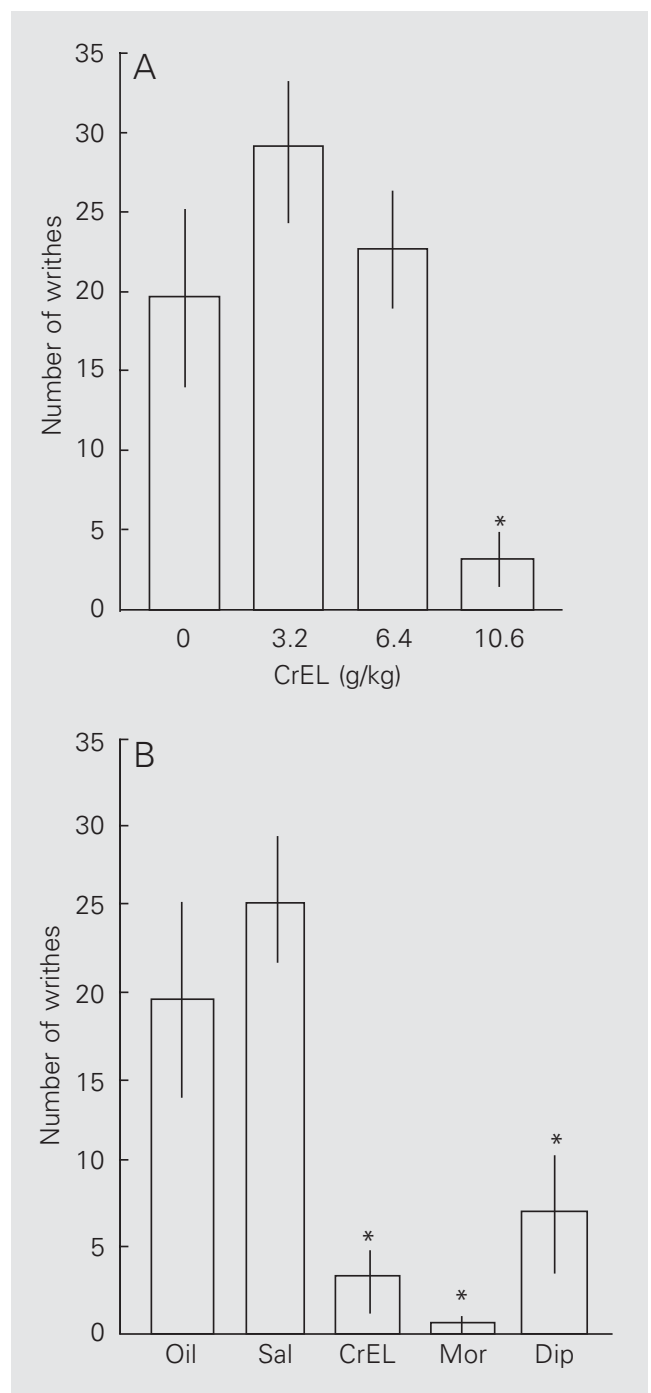

Figure 1. Effect of Cremophor EL (CrEL) (A) and comparison between the effects of $\mathrm{CrEL}$ $(10.6 \mathrm{~g} / \mathrm{kg})$, morphine $(20 \mathrm{mg} /$ $\mathrm{kg}$ ) and dipyrone $(300 \mathrm{mg} / \mathrm{kg})(\mathrm{B})$ on the number of writhes induced by acetic acid in mice. ${ }^{*} \mathrm{P}<0.005$ compared with the Oil group (A) or Oil and Sal groups (B) (Student-Newman-Keuls test). Data are reported as means \pm SEM for 5 animals in each group. Oil: castor oil, Sal: $0.9 \%$ saline, Mor: morphine, Dip: dipyrone. 
causes antinociception in both phasic and tonic antinociceptive tests is quite interesting, since this is a characteristic of strong analgesics, such as opioid agonists $(13,14)$. In fact, in the present study morphine, dipyrone and CrEL caused antinociception in both tests. Other mild analgesics such as aspirin and salicylic acid lack an antinociceptive action in thermally motivated tests such as the tail immersion, tail-flick and hotplate tests, but have significant antinociceptive activity in tonic tests, which are characterized by the direct chemical stimulation of nociceptors (15). Since it has been reported that thermally motivated and tonic tests elicit the selective stimulation of $\mathrm{A} \delta$ and $\mathrm{C}$ fibers, respectively $(16,17)$, it is tempting to pro-

Figure 2. Effect of Cremophor $\mathrm{EL}(\mathrm{CrEL})$ (A) and comparison between the effects of $\mathrm{CrEL}$ (10.6 g/kg), morphine $(20 \mathrm{mg} / \mathrm{kg})$ and dipyrone $(300 \mathrm{mg} / \mathrm{kg})(\mathrm{B})$ on the latency to withdraw the tail in the tail immersion test in mice. ${ }^{*} P<0.05$ compared with the Oil group (A) or Oil and Sal groups (B) (Mann-Whitney U-test). Data are reported as the median \pm interquartile range for 6-7 animals in each group. Oil: castor oil, Sal: 0.9\% saline, Mor: morphine, Dip: dipyrone.

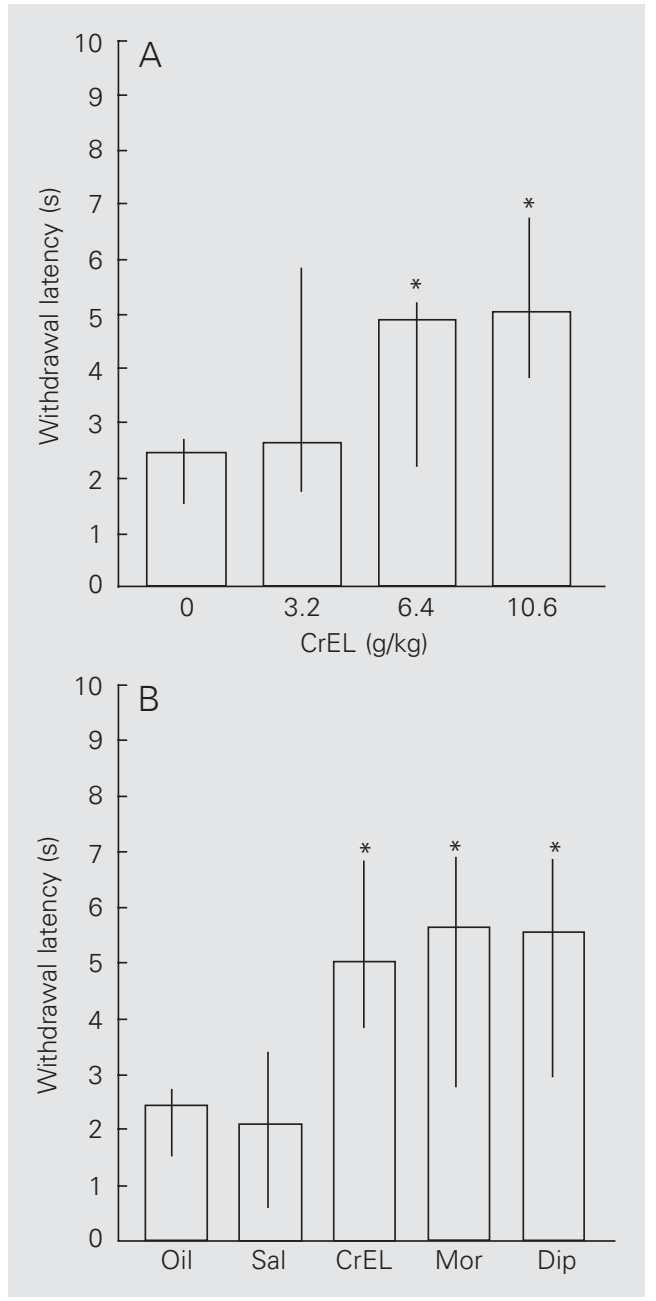

pose that CrEL or its metabolites may interfere with the transmission of both fibers or with a common pathway, such as spinal and thalamic pathways.

It is important to emphasize, however, that recent studies have shown that systemic concentrations of $\mathrm{CrEL}$ are undetectable following oral administration to both mice and humans $(9,18)$. Therefore, since previous work has demonstrated that polyoxyethylated-type surfactants are metabolized in the intestine by pancreatic lipase into the fatty acid residue and a polyol moiety, with only less than $4 \%$ of the administered dose being excreted unchanged into urine (19), it is possible that one of these metabolites, and not CrEL itself, is responsible for the antinociceptive effect of CrEL described here. This view is corroborated by the finding that injection of $10 \mathrm{ml} / \mathrm{kg}$ of an intravenous preparation of CrEL $(10 \%, v / v)$ has no antinociceptive activity (4).

In addition, it has been reported that $\mathrm{CrEL}$ $(2,8)$, and one of its constituents, ethylene oxide (20), alter nerve conduction, and this finding may be relevant to explain the antinociceptive effect of CrEL described here. However, beneficial effects of CrEL on nerve conduction of diabetic animals have also been reported, indicating that further studies are needed to clarify this point.

An important issue regarding the behavioral effects of CrEL is that it does not cause motor impairment, evaluated by spontaneous locomotor behavior in the open field or forced locomotion in the Rotorod. This lack of effect on spontaneous and forced locomotion supports the view that the antinociceptive effect of orally administered CrEL involves the selective modulation of nociceptive pathways.

The present report describes that orally administered CrEL induces antinociception comparable to that caused by morphine ( 20 $\mathrm{mg} / \mathrm{kg}$, by gavage) and dipyrone $(300 \mathrm{mg} / \mathrm{kg}$, by gavage), and that the effect does not seem to be due to motor impairment. It is impor- 
tant to point out that, although 6.4 and 10.6 $\mathrm{g} / \mathrm{kg}$ CrEL, which are relatively high doses, caused antinociception in the present study, one should be careful when evaluating the

\section{effects of potential antinociceptive agents dissolved in this vehicle and administered by the oral route.}

\section{References}

1. Sparreboom A, Loos WJ, Verweij J, de Vos Al, Van der Burg MEL, Stoter G \& Nooter K (1998). Quantitation of Cremophor EL in human plasma samples using a colorimetric dye-binding microassay. Analytical Biochemistry, 255: 171-175.

2. Authier N, Gillet J-P, Fialip J, Eschalier A \& Coudore F (2000). Description of a short-term Taxol-induced nociceptive neuropathy in rats. Brain Research, 887: 239-249.

3. Windebank AJ, Blexrud MD \& de Groen PC (1994). Potential neurotoxicity of the solvent vehicle for cyclosporine. Journal of Pharmacology and Experimental Therapeutics, 268: 1051-1056.

4. Burstein SH, Friderichs E, Kogel B, Schneider J \& Selve N (1998). Analgesic effects of $1^{\prime}, 1^{\prime}$-dimethylheptyl-delta8-THC-11-oic acid (CT3) in mice. Life Sciences, 63: 161-168.

5. Janssen PAJ, Niemeggers CJE \& Dony JGH (1963). The inhibitory effect of fentanyl and other morphine-like analgesics on the warm water induced tail withdrawal reflex in rats. Arzneimittel-Forschung, 13: 502-507.

6. Mounier P, Laroche D, Divanon F, Mosquet B, Vergnaud MC, EsseComlan A, Piquet MA \& Bricard H (1995). Anaphylactoid reactions to an injectable solution of a cremophor-containing solution of multivitamins. Therapie, 55: 571-573.

7. Zhao FK, Chuang LF, Israel M \& Chuang RY (1989). Cremophor EL, a widely used parenteral vehicle, is a potent inhibitor of protein kinase C. Biochemical and Biophysical Research Communications, 159: 1359-1367.

8. Jack AM, Cameron NE \& Cotter MA (1999). Effects of the diacylglycerol complexing agent, Cremophor, on nerve conduction velocity and perfusion in diabetic rats. Journal of Diabetes and its Complications, 13: 2-9.

9. Sparreboom A, van Asperen J, Mayer U, Schinkel AH, Smit JW, Meijer DKF, Borst P, Nooijen WJ, Beijnen JH \& Tellingen OV (1997). Limited oral bioavailability and active epithelial excretion of paclitaxel (Taxol) caused by P-glycoprotein in the intestine. Proceedings of the National Academy of Sciences, USA, 94: 2031-2035.

10. Zimmermann M (1983). Ethical guidelines for investigation of exper- imental pain in conscious animals. Pain 16: 109-110.

11. Rubin MA, Albach CA, Berleze DB, Bonacorso HG, Bittencourt SRT, Queiroz CMT, Maixner AE \& Mello CF (2000). Anxiolytic-like effects of 4-phenyl-2-trichloromethyl-3H-1,5-benzodiazepine hydrogen sulfate in mice. Brazilian Journal of Medical and Biological Research, 33: 1069-1073

12. Hayashi G \& Takemori AE (1971). The type of analgesic-receptor interaction involved in certain analgesic assays. European Journal of Pharmacology, 16: 63-66.

13. Hunskaar S, Berge O-G \& Hole K (1986). A modified hot-plate test sensitive to mild analgesics. Behavioural Brain Research, 21: 101108.

14. Hunskaar S \& Hole K (1987). The formalin test in mice: dissociation between inflammatory and non-inflammatory pain. Pain, 30: 103114.

15. Akman H, Aksu F, Gultekin I, Ozbek H, Oral U, Doran F \& Baysal F (1996). A possible central antinociceptive effect of dipyrone in mice. Pharmacology, 53: 71-78.

16. Yeomans DC, Pirec V \& Proudfit HK (1996). Nociceptive responses to high and low rates of noxious cutaneous heating are mediated by different nociceptors in the rat: behavioral evidence. Pain, 68: 133140.

17. Yeomans DC, Pirec V \& Proudfit HK (1996). Nociceptive responses to high and low rates of noxious cutaneous heating are mediated by different nociceptors in the rat: electrophysiological evidence. Pain, 68: 141-150.

18. Terwogt JMM, Beijnen JH, Huinink WWB, Rosing $H$ \& Schellens JHM (1998). Co-administration of cyclosporin enables oral therapy with paclitaxel. Lancet, 352: 285.

19. Asinger F (1967). Chemistry, Physics and Application of Surface Active Substances. Vol. 3. Gordon and Breach, London, UK.

20. Ohnishi A \& Murai Y (1993). Polyneuropathy due to ethyl and 351127/ 97-6ene oxide, propylene oxide, and butylene oxide. Environmental Research, 60: 242-247. 